\title{
Optimization of Culture Conditions for Total Carotenoid Amount Using Response Surface Methodology in Green Microalgae / Ankistrodesmus convolutus
}

\author{
Neslihan Sener ${ }^{1}$, Zeliha Demirel² (D), Esra Imamoglu² (D), Meltem Conk Dalay² (D) \\ Cite this article as: Sener, N., Demirel, Z., Imamoglu, E., \& Conk Dalay, M. (2022). Optimization of culture conditions for total carotenoid amount \\ using response surface methodology in green microalgae / Ankistrodesmus convolutes. Aquatic Sciences and Engineering, $37(1), 29-37$.
}

\author{
ORCID IDs of the author: \\ N.S. 0000-0002-4898-9562; \\ Z. D. $0000-0003-3675-7315$ \\ E. I. 0000-0001-8759-7388; \\ M.C.D. 0000-0002-1718-7292 \\ ${ }^{1}$ Ege University, Graduate School \\ of Natural and Applied Sciences, \\ Department of Biotechnology, Bornova, \\ Izmir, Turkey \\ ${ }^{2}$ Ege University, Faculty of Engineering, \\ Department of Bioengineering, Bornova, \\ Izmir, Turkey \\ Submitted: \\ 25.08.2020 \\ Revision Requested: \\ 13.02.2021 \\ Last Revision Received: \\ 06.04.2021 \\ Accepted: \\ 13.05.2021 \\ Online Published: \\ 31.12.2021 \\ Correspondence: \\ Zeliha Demirel \\ E-mail: \\ zelihademirel@gmail.com
}

\begin{abstract}
Commercial carotenoids of green microalgae have become significant especially for their applications in the cosmetic, pharmaceutical, food and feed industries. Effects of physical and chemical parameters on carotenoid contents in isolated microalgal species have been investigated. The variables of shaking rate, nitrogen concentration and light intensity affect biomass production and the synthesis of carotenoids in the green microalgae were investigated using the statistical design by Box-Behnken (BBD) employing Response Surface Methodology (RSM). Furthermore, the optimized cultivation conditions using BBD for Chlorella vulgaris, Ankistrodesmus convolutus, Dunaliella salina, Tetraselmis striata were determined using the spectrophotometric method to enhance carotenoid concentration. A. convolutus within the green algae was detected with the highest carotenoid concentration. The optimum conditions results indicated that the growth of $A$. convolutus $(0.55 \mathrm{mg} / \mathrm{L})$ and production of total carotenoids ( $25.1138 \mathrm{mg} / \mathrm{g}$ biomass) were found at the stirrer rate of $100 \mathrm{rpm}$ under the light intensity of $100 \mu \mathrm{E} / \mathrm{m}^{2} \mathrm{~s}$, and in the nutrient component of $8.82 \mathrm{mM}$ $\mathrm{NaNO}_{3}$. These conditions were validated experimentally for total carotenoid yield $(24.13 \mathrm{mg} / \mathrm{g}$ biomass). After that the production was performed in a flat-plate photobioreactor with a volume of $6 \mathrm{~L}$ based on the optimized conditions and the carotenoid profile was defined by HPLC-DAD using standards such as violaxanthin, astaxanthin and $\beta$-carotene. This study proposes that the RSM approach can be used to define optimal conditions for large-scale production of carotenoids by $A$. convolutus.
\end{abstract}

Keywords: Chlorella vulgaris, Ankistrodesmus convolutus, Dunaliella salina, Tetraselmis striata, Carotenoid, Optimization, Photobioreactor

\section{INTRODUCTION}

Microalgae has a number of natural bioactive molecules, especially carotenoids. Furthermore microalgal carotenoids can provide lots of properties as anti-virals, antimicrobials, anti-inflammatory, anti-oxidant, provitamin A and anti-cancer (Cezare-Gomes et al., 2019). Additionally, microalgae cultivation can be preferred compared to plant cultivation when as algae has many abilities of such as higher biomass production, faster growth and requiring a small- er area of crop (Coelho et al., 2019). Microalgae can create two types of carotenoids: primary carotenoids as photosynthetic apparatus, and secondary carotenoids whenever cells are exposed to stress conditions (Sun et al., 2018; Novoveská et al., 2019). Under various stress conditions such as light intensity, salinity, temperature, nutrient limitation promotes the carotenoid production for microalgae cultivation (Ambati et al., 2018). The demand for natural products, health protecting biomolecules due to healthy and functional food and nutraceuti- 
cals bazaar has enhanced increased in the recent years. Many microalgae species are usually identified as safe by the US Food and Drug Administration (GRAS; www.fda.gov). Therefore, the global carotenoid market is anticipated to increase with an annual buy hold gain of 3.9\% from 2014 to 2019 (Di Lena et al., 2019). Carotenoids can be divided into two groups: carotene ( $\alpha$-carotene, $\beta$-carotene and lycopene) and phylloxanthin (astaxanthin, lutein, fucoxanthin and zeaxanthin) and are used in different industries as natural colorants and for their bioactive molecule properties in nutraceuticals, food, feed and cosmetics. For this reason, the investigation of novel natural sources of carotenoids is increasingly resultant in demand (Di Lena et al., 2019).

Response surface methodology (RSM) is both the design of mathematics and statistics concerned with assessing issues due to dependence on several independent variables with an objective to maximize the process variables for approaching optimum response (Eren Şenaras, 2019). Response surface design, which has a center point involved for each independent variable along with the high and low points, requires three trials for each independent variable. In general, a central composite design (CCD) and a Box-Behnken designs (BBD) are the two most reliable and efficient techniques utilized in RSM (Şahin et al., 2019). RSM has decreased the number of experiment runs as a result of saving time, material and labour (Bajwa et al., 2019).

This study had three aims : (I) to cultivate different green microalgae and determine the growth curve, (II) to investigate the carotenoid concentrations of algae enhanced by statistical methods (III) to determine carotenoid profile using HPLC-DAD.

\section{MATERIAL AND METHODS}

\section{Cultivation of microalgae and measurement of growth rate}

All microalgae species were isolated from Turkish fresh and marine water. Strains were added to the culture collection for long term preservation. Green microalgae were provided by the Ege University Microalgae Culture Collection EGEMACC (htps://egemacc.com/cultures.php). The species of microalgae and culture collection codes were given as Chlorella vulgaris Beyerinck [Beijerinck] 1890 EGEMACC-53, Ankistrodesmus convolutus Corda 1838 EGEMACC-52, Dunaliella salina (Dunal) Teodoresco 1905 EGEMACC-84, Tetraselmis striata Butcher 1959 EGEMACC-42.

Both C. vulgaris and A. convolutus were cultivated in Blue-Green Algae Medium-BG-11 (https://utex.org/products/bg-11-medium?variant=30991786868826) (17.65 $\mathrm{mM} \mathrm{NaNO}_{3}$ sodium nitrate) and in a medium of $300 \mathrm{~mL}$ flask at $100 \mathrm{rpm}$ in a shaker incubator at $20 \pm 2{ }^{\circ} \mathrm{C}$ under $20 \mu \mathrm{E} / \mathrm{m}^{2} \mathrm{~s}$ light intensity while T. striata and $D$. salina were grown in DBG-11 (Sea salt added BG-11) and Daigo's IMK Medium (Nihon Pharmaceutical Co., Ltd) media made with artificial seawater for dissolving $22 \mathrm{~g} / \mathrm{L}$ sea salt (Marinium reef) with the same cultured conditions, respectively. The inoculum was added in a bubble-column photobioreactor $(2 \mathrm{~L})$ and cultivated under the light intensity of $100 \mu \mathrm{E} / \mathrm{m}^{2} \mathrm{~s}$, at $20 \pm 2{ }^{\circ} \mathrm{C}$, and with the aeration system of $3 \mathrm{~L} / \mathrm{min}$. The growth of microalgae was pursued by counting microalgae cells, optic turbidity (at 600 $\mathrm{nm})$, chlorophyll and carotenoid analysis at 2-day intervals over the period of 20 days. Then, cells upon reaching the stationary phase were harvested with centrifuge (ProResearch, By Centurion Scientific Ltd, UK), resuspended with fresh medium and cell concentration were counted with hemocytometer, and used as inoculum at $10^{7}$ cell/mL for further experiments. The inoculum of microalgae was incubated under the RSM conditions for 11 days in a shaker incubator.

The microalgae specific growth rate $(\mu)$ was calculated from the initial logarithmic phase of growth curve for at least 3 days and the cell death was neglected as

$$
\mu=(\ln X 2-\ln X 1) /(T 2-T 1)
$$

Where $X_{2}$ is the last cell concentration at time T2, $X_{1}$ is the beginning cell concentration at time T1 (Demirel et al., 2018). Doubling time (DT) was also calculated as DT $=\underline{\ln 2}$

$$
\mu
$$

Dry weight was defined via filtering a $5 \mathrm{~mL}$ culture through preweighed Glass Microfiber filters, grade GF/C (GF-3, Macherey-Nagel), then washed with distilled water and dried at $65 \pm 2^{\circ} \mathrm{C}$ to a constant weight.

\section{Spectroscopic determination of carotenoid}

$10 \mathrm{~mL}$ of culture was centrifuged for $15 \mathrm{~min}$ at $4000 \mathrm{~g}$ and then the pelted was suspended in Dimethyl sulphoxide (DMSO) for 45 min in an ultrasonic bath at $45^{\circ} \mathrm{C}$ in darkness, followed by centrifugation. The optic turbidity of the supernatant was determined at 665, 649 and $480 \mathrm{~nm}$. Chlorophyll a \& b and carotenoid concentration was calculated using the equation according to Wellburg (1994).

\section{Statistical analysis}

The optimization of the carotenoid process was identified by Response Surface Methodology (RSM) based on Box-Behnken Design (BBD) by the aid of software package Design Expert (version 7.0.0; StatEase Inc., Minneapolis, MN, USA). BBD analysis was used to implement the impact on three independent parameters (shaking rate between the range of 100-250 rpm, light intensity between the range of $100-400 \mu \mathrm{E} / \mathrm{m}^{2} \mathrm{~s}$, and nitrate $\left(\mathrm{NaNO}_{3}\right)$ concentration between the ranges of 0-17.65 mM) in 15 runs.

\section{Flat-plate photobioreactor (PBR) for Ankistrodesmus convolutus} Flat-plate photobioreactor (PBR) composed of plexiglas enclosed in a rigid metal frame with a volume of $6 \mathrm{~L}$ was equipped with an online controller (Biosis, Pikolab, Turkey). A temperature-dissolved oxygen probe and $\mathrm{pH}$ probe were located in the upper part of the PBR. The culture $\mathrm{pH}$ and dissolved oxygen were measured by a sensor, whereas temperature was maintained at $21 \pm 2{ }^{\circ} \mathrm{C}$ in the temperature-controlled incubator. PBR made of stainless steel was autoclaved at $121^{\circ} \mathrm{C}$ for 15 min prior to use. Ankistrodesmus convolutus culture was prepared using 11.06 mM nitrogen concentration in BG-11 and mixed by only air at an aeration rate of $4 \mathrm{~L} / \mathrm{min}$ and controlled by a flow meter (RST electronic Ltd, LZM-6T Turkey). Illumination was provided on the frontal plate by a light emitting diode lamp (LED-Cata 10W CT5254) with a light intensity of $200.94 \mu \mathrm{E} / \mathrm{m}^{2} \mathrm{~s}$.

After 11 days, biomass was harvested by centrifugation. Paste biomass was stored in a freezer at $-20^{\circ} \mathrm{C}$ and then dried using a freeze-dryer (Christ Alpha 1-2 LD plus, Germany). 


\section{Determination of carotenoid profiles}

$0.02 \mathrm{~g}$ microalgae powder and $0.02 \mathrm{~g} \mathrm{CaCO}_{3}$ were used with methanol:dichloromethane (MeOH:DCM) (3:1) for the extraction of carotenoids from $A$. convutulus. The cell was lysed using $1 \mathrm{~mm}$ diameter glass bead at maximum speed for 10 minutes. The solution was centrifuged at $6000 \mathrm{rpm}$ for $20 \mathrm{~min}$. The residue was repeatedly extracted until the pellet became colorless. The supernatants were collected and combined. The supernatant was then pushed through a $0.45 \mu \mathrm{m}$ PTFE filters and carotenoid profiles was analyzed by HPLC-DAD (Thermo Scientific Ultimate 3000, Diode Array Detector) using Carotenoid column (YMC C ${ }_{30 \prime}$ $5 \mathrm{~mm}, 250 \times 4.6 \mathrm{~mm}$ ID) manufactured by Waters (Milford, MA, USA). The column temperature was set at $20.0^{\circ} \mathrm{C}$. For the carotenoid and chlorophyll assay, Solvent A DCM: $\mathrm{MeOH}$ : acetonitrile (ACN): water (5:85:5.5:4.5) and Solvent B DCM: $\mathrm{MeOH}$ : ACN: water (22:28:45.5:4.5) were used as the mobile phase and run at a flow rate of $1 \mathrm{~mL} / \mathrm{min}$. The gradient conditions were $100 \% A$ and $0 \% \mathrm{~B}$ for $8 \mathrm{~min}$, decreased to $0 \% \mathrm{~A}$ and increased to $100 \% \mathrm{~B}$ in 12 $\mathrm{min}, 100 \% \mathrm{~B}$ maintained for $30 \mathrm{~min}$. The total analysis period was $50 \mathrm{~min}$. Under these conditions, standard chlorophyll-a, chlorophyll b, $\beta$-carotene, violaxanthin, astaxanthin (Sigma-Aldrich) were given maximum absorbance at $400-480 \mathrm{~nm}$. For calibration, a standard (0.1-20 mg/L) was prepared from the stock solution and later the standard curve defined concentration of standard chemicals (Erdoğan et al., 2015).

\section{RESULTS AND DISCUSSION}

This study was realized in three step: (I) green microalgae was cultivated and growth kinetics were determined, (II) the carotenoid concentration of algae was evaluated to enhance various growth conditions using response surface methodology (RSM) (III) microalgae including maximized carotenoid was grown in flat-plate photobioreactors and carotenoid profile was defined using HPLC-DAD.

\section{Growth of microalgae}

The green microalgae was cultivated over the period of 20 days for the determination of growth rates. Fresh water microalgae Chlorella vulgaris and Ankistrodesmus convolutus reached faster doubling times than marine or brackish water microalgae Dunaliella salina, Tetraselmis striata (Table 1). Maximum total carotenoid of microalgae $(9.27 \mathrm{mg} / \mathrm{L})$ was found for $C$. vulgaris with the highest cell concentration, although the highest dried weight was obtained for $A$. convolutus. The maximum cell concentration of $2 \times 10^{7}$ cell $/ \mathrm{mL}$ of $C$. vulgaris was obtained in the BG-11 medium containing $17.65 \mathrm{mM}$ nitrogen concentration under light intensity of $100 \mu \mathrm{E} / \mathrm{m}^{2} \mathrm{~s}$ on the $18^{\text {th }}$ day of cultivation while the lowest specific growth rate of $T$. striata was reached in the DBG-11 media containing the same nitrogen concentration and under the same light intensity, as shown in Fig. 1. Fig. 1A and 1B were used to state the specific growth rate of the algae. The microalgae cells determined the stationary phase to use as inoculum for A Box-Behnken design experiments.

\section{Determination of carotenoid concentration and statistical analysis}

A Box-Behnken design (BBD) is a three-level full factorial (low, medium and high) design that is implemented to state the nature of the response surface in the trial area. BBD with 15 sets ensures sav-

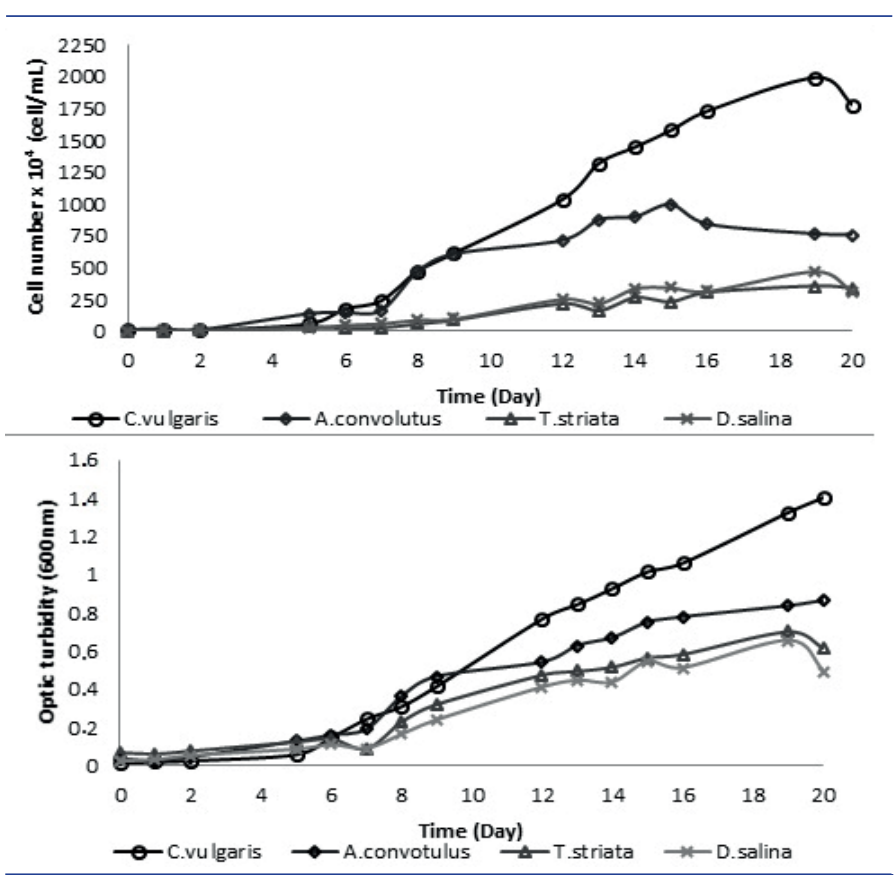

Figure 1. Growth curves of green microalgae in a bubblecolumn photobioreactor under the light intensity of $100 \mu \mathrm{E} / \mathrm{m} 2 \mathrm{~s}$ at $20 \pm 2{ }^{\circ} \mathrm{C} \mathrm{A}$ : cell number and B: optic turbidity.

Table 1. Growth kinetics of microalgae.

\begin{tabular}{|c|c|c|c|c|c|}
\hline Microalgae & 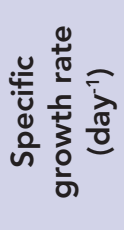 & 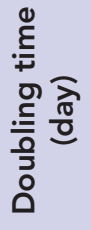 & 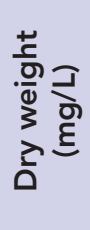 & 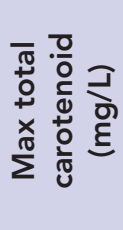 & 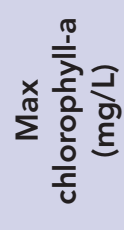 \\
\hline$j \frac{\frac{0}{\frac{0}{0}}}{\frac{0}{3}}$ & 0.33 & 2.10 & 0.47 & 9.27 & 19.35 \\
\hline 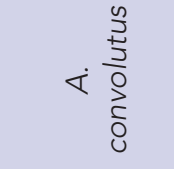 & 0.44 & 1.58 & 0.55 & 6.54 & 19.86 \\
\hline$ト \cdot \frac{\pi}{\stackrel{\pi}{ \pm}}$ & 0.20 & 3.47 & 0.33 & 7.83 & 17.44 \\
\hline 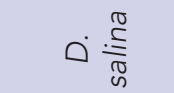 & 0.21 & 3.30 & 0.38 & 8.28 & 14.57 \\
\hline
\end{tabular}

ing on time in comparison with 20 sets of central composite design due to fewer factors of the design determination (Keskin Gündoğdu et al., 2016). The BBD was preferred to study the interaction effects of the parameters. . This experimental design was created to obtain the highest containing carotenoid concentration in the shortest time. This study was enhanced to evaluate carotenoid concentration at different shaking rates, light intensities, and sodi- 
um nitrate concentration levels. BBD and response surface methodology were performed to design the experiments and optimize the cultivation process for C. vulgaris, A. convolutus, T. striata and D. salina. As seen from Table 2, carotenoid concentration (mg/g dried biomass) of the cells were obtained in run $7(25.1138 \mathrm{mg} / \mathrm{g}$ biomass) and set 10 ( $24.8029 \mathrm{mg} / \mathrm{g}$ biomass) for $\mathrm{A}$. convutulus and C. vulgaris, respectively.

Different mixing rates $A$ - rpm $(100,175,250), 3$ different light intensities; $B-\mu E / m^{2} s(100,250,400)$ and 3 different sodium nitrate concentrations; $\mathrm{C}-\mathrm{mM}(0,8.82,17.65)$ were tested (Table 2). A t otal of 15 experimental runs were performed to optimize the range and levels of selected variables. Also, the order of treatments was regulated incidentally.

The Analysis of Variance (ANOVA) for the model Equivalent (1) of four green microalgae strains observed a good fit between the models and the experimental values.

The experimental results of C. vulgaris (Eq 1.1), A. convotulus (Eq 1.2), T. striata (Eq 1.3) and D. salina (Eq. 1.4) the following response surface model, was defined in the symbol factors $(A ; B ; C)$ :

$M_{\text {Chlorella }}=19.10117-0.21897 * A+0.016477 * B+2.63118 * C+3.13471 * 10^{-3} * A * B-4.44918 *$ $10^{-3} * A * C-4.51924 * 10^{-4} * B * C+7.31595 * 10^{-4} * A^{2}-5.33986 * 10^{-7} * B^{2}-0.092517 * C^{2}$ $M_{\text {Ankistrodesmus }}=56.94909-0.42121 * A-0.014548 * B-0.34569 * C+1.27455 * 10^{-4} * A * B+2.02616 *$ $10^{-3} * A * C+2.45561 * 10^{-5} * B * C+1.07836 * 10^{-3} * A^{2}-4.37888 * 10^{-5} * B^{2}-7.49953 * 10^{-3} * C^{2}$

$(1.2)$
$M_{\text {Tetraselmis }}=-11.14775+0.096766 * A+0.046668 * B+0.69212 * C-6.19064 * 10^{-5} * A * B+2.82325 *$ $10^{-5} * A * C-1.23110 * 10^{-4} * B * C-2.01400 * 10^{-4} * A^{2}-6.87095 * 10^{-5} * B^{2}-0.035297 * C^{2}(1.3)$ $M_{\text {Dunatiella }}=4.28276+0.070757 * A++9.44808 * 10^{-3} * B+0.17251 * C-6.13871 * 10^{-5} * A * B+$ $M_{\text {Dunaliella }}=4.28276+0.070757 * A++9.44808 * 10^{-3} * B+0.17251 * C-6.13871 * 10^{-5} * A * B+$
$1.96848 * 10^{-4} * A * C-1.79202 * 10^{-4} * B * C-1.46438 * 10^{-4} * A^{2}+1.16302 * 10^{-5} * B^{2}-9.65502 *$ $10^{-3} * C^{2}(1.4)$

The regression balance that reflects the model for carotenoid concentration of $C$. vulgaris, $A$. convotulus, $T$. striata and $D$. salina are seen in Eq 1.1, 1.2, 1.3, 1.4 and $R^{2}$ adj $=0.92,0.91,0.93,0.94$, respectively. This result of adjusted $R^{2}$ demonstrates that the model is highly explainable by analyzed variables. When, adjusted $R^{2}$ value is close to forecast 1 , the more powerful the design is and the stronger it estimates the response (Demirel et. al., 2018). The re- gression coefficient $\left(R^{2}>0.90\right)$ was found to be within acceptable limits in all models. Variables were evaluated as remarkable when all model $p$ values of the variable were less than 0.03 (Table 3).

ANOVA was used to peruse the statistical significance of regression coefficients via performing the F-test, $t$ he most accurate model formed and exhibited in graphical representations with contour plots of factors that represent their relative influence and optimal parameter values. A quadratic polynomial empirical model was used in stated optimum conditions for carotenoid $\mathrm{mg} / \mathrm{g}$ biomass $C$. vulgaris, A. convolutus, T. striata and $D$. salina.

Optimum stress parameters of C. vulgaris were determined as mixing speed of $100 \mathrm{rpm}$, light intensity of $400 \mu \mathrm{E} / \mathrm{m}^{2} \mathrm{~s}$ and nitrogen concentration of $10.85 \mathrm{mM}$ when maximum carotenoid amount was predicted in the experimental design (Table 4). Three-dimensional graphs obtained according to statistical analysis results are shown in Fig. 2. When these graphs were analyzed, it was found that both the rise of the shaking rate and light intensity increased the amount of carotenoid despite the fact that the increase in nitrogen concentration had a negative effect.

The optimization data for the maximum carotenoid value for $A$. convolutus was defined at mixing speed of $250 \mathrm{rpm}$, under light intensity of $200.94 \mu \mathrm{E} / \mathrm{m}^{2} \mathrm{~s}$, using nitrogen concentration of 11.06 $\mathrm{mM}$. The three-dimensional graphs obtained according to the statistical analysis results for this microalgae species are shown in Fig. 3. When the graphs were examined, it was found that the carotenoid yield decreased at the highest values of light intensity and nitrogen scarcity was a significant effect on stress parameters for this species.

The optimum parameters of T. striata were determined by targeting the maximum mg carotenoid amount per $\mathrm{g}$ of dried biomass and the optimum parameters found through 220.17 rpm mixing speed, $212.78 \mu \mathrm{E} / \mathrm{m}^{2} \mathrm{~s}$ light intensity and $9.15 \mathrm{mM}$ nitrogen con-

Table 2. Experimental data and levels in the response surface design.

\begin{tabular}{|c|c|c|c|c|c|c|c|}
\hline Run & $\begin{array}{l}\text { Shaking } \\
\text { rate-A } \\
\text { (rpm) }\end{array}$ & $\begin{array}{c}\text { Light } \\
\text { intensity-B } \\
\left(\mu \mathrm{E} / \mathrm{m}^{2} \mathrm{~s}\right)\end{array}$ & $\begin{array}{c}\text { Nitrogen } \\
\text { concentration-C } \\
(\mathrm{mM})\end{array}$ & $\begin{array}{c}\text { C. vulgaris } \\
\mathrm{mg} / \mathrm{g} \text { biomass }\end{array}$ & $\begin{array}{l}\text { A. convolutus } \\
\mathrm{mg} / \mathrm{g} \text { biomass }\end{array}$ & $\begin{array}{c}\text { T. striata } \\
\mathrm{mg} / \mathrm{g} \text { biomass }\end{array}$ & $\begin{array}{c}\text { D. salina } \\
\text { mg/g biomass }\end{array}$ \\
\hline 1 & 100 & 400 & 8.82 & 21.4375 & 14.958 & 4.11924 & 4.50883 \\
\hline 2 & 250 & 100 & 8.82 & 19.6464 & 22.3609 & 6.74322 & 5.14317 \\
\hline 3 & 250 & 250 & 17.65 & 10.1538 & 21.3272 & 4.01902 & 3.65652 \\
\hline 4 & 175 & 100 & 0.00 & 5.8838 & 14.7345 & 2.53533 & 3.53524 \\
\hline 5 & 175 & 100 & 17.65 & 9.09091 & 13.217 & 3.80448 & 3.57954 \\
\hline 6 & 175 & 400 & 0.00 & 11.2538 & 13.605 & 2.75881 & 5.30923 \\
\hline 7 & 100 & 100 & 8.82 & 15.6916 & 25.1138 & 2.38812 & 2.66377 \\
\hline 8 & 100 & 250 & 17.65 & 19.0038 & 16.9722 & 3.62919 & 2.72584 \\
\hline 9 & 175 & 250 & 8.82 & 16.7914 & 15.0128 & 7.41362 & 4.69743 \\
\hline 10 & 250 & 400 & 8.82 & 24.8029 & 17.9407 & 5.68854 & 4.2258 \\
\hline 11 & 175 & 250 & 8.82 & 16.7914 & 15.0128 & 7.41362 & 4.69743 \\
\hline 12 & 250 & 250 & 0.00 & 14.2885 & 21.3348 & 3.39698 & 3.25713 \\
\hline 13 & 175 & 250 & 8.82 & 16.7914 & 15.0128 & 7.41362 & 4.69743 \\
\hline 14 & 100 & 250 & 0.00 & 11.3593 & 22.344 & 3.08189 & 2.8476 \\
\hline 15 & 175 & 400 & 17.65 & 12.068 & 12.2175 & 3.3761 & 4.40466 \\
\hline
\end{tabular}




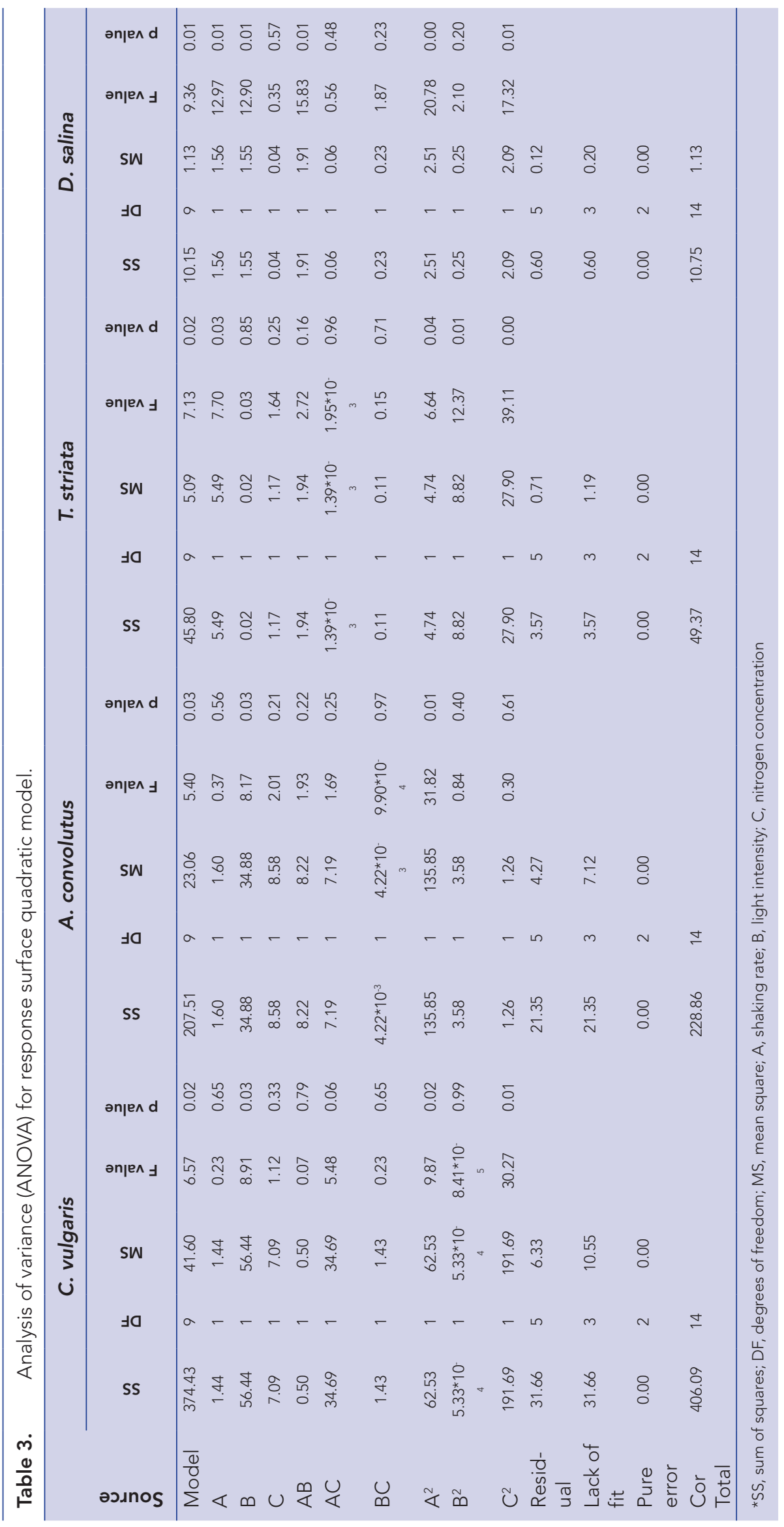



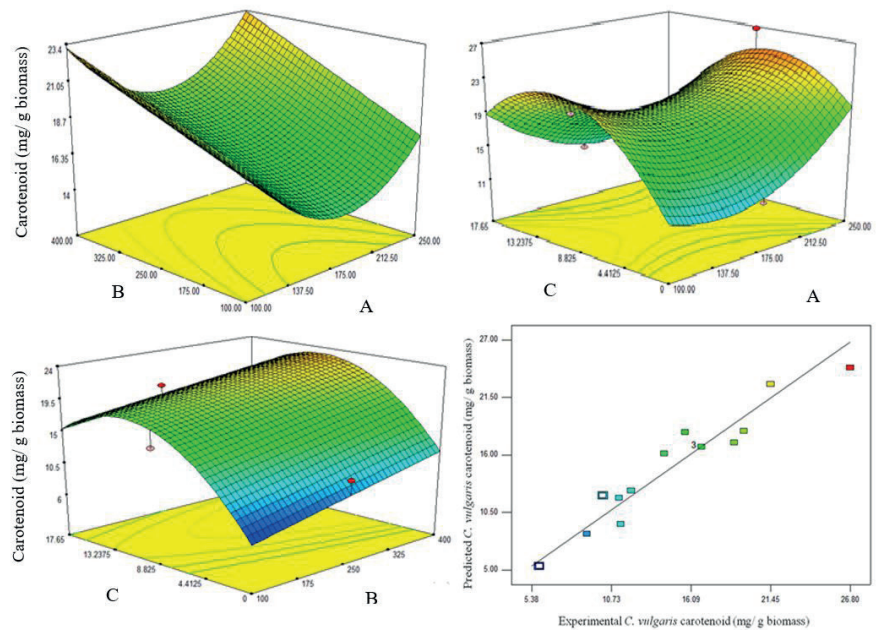

Figure 2. 3D response surface plot of BBD showing the mutual effects A: Shaking of rate (rpm), B: light intensity ( $\mu \mathrm{E} /$ $\mathrm{m}^{2} \mathrm{~s}$ ) and $\mathrm{C}$ : nitrogen concentration ( $\mathrm{mM}$ ) on carotenoid concentration of Chlorella vulgaris.
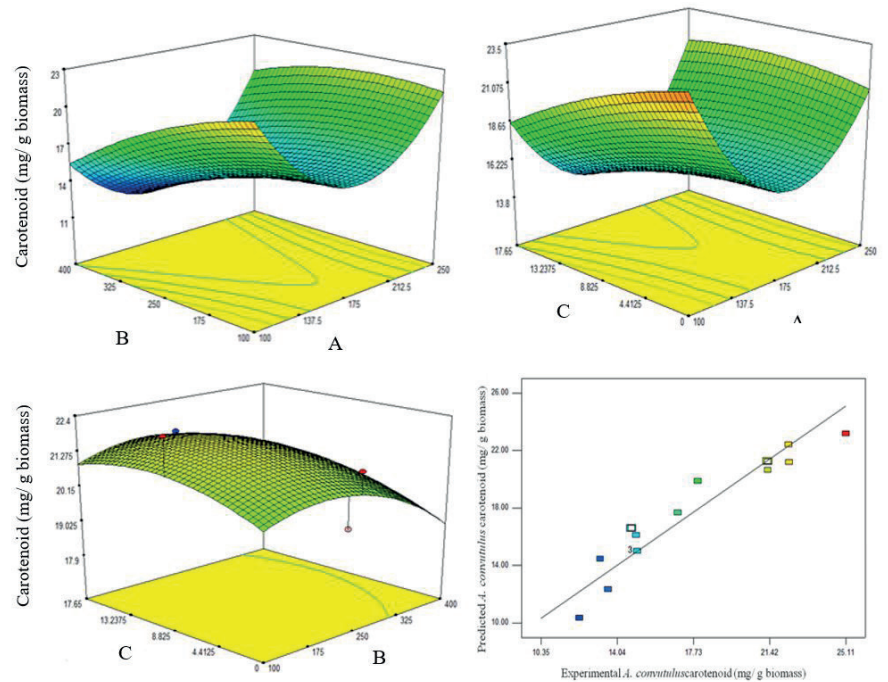

Figure 3. $3 D$ response surface plot of $B B D$ showing the mutual effects of $A$ : Shaking rate (rpm), B: light intensity $(\mu \mathrm{E} /$ $\mathrm{m}^{2} \mathrm{~s}$ ) and $\mathrm{C}$ : nitrogen concentration $(\mathrm{mM})$ on carotenoid concentration of Ankistrodesmus convotulus.

centration. The three-dimensional graphs obtained from the statistical analysis of T. striata are shown in Fig. 4. Nitrogen concentration was detected to be a sensitive parameter for $T$. striata while the carotenoid yield decreased considerably under low nitrogen concentration. For D. salina, nitrogen scarcity was found to be less effective than other stress parameters. As shown in Fig. 5, increasing light intensity appeared to be effective for carotenoid yield.

Wang et al. 2019 reported that optimized medium composition by Central Composite Design (CCD) for freshwater alga Desmodesmus armatus was stated indicated the nitrate concentration of $0.93 \mathrm{~g} \mathrm{~L}^{-1}$ under the light intensity of $108 \mu \mathrm{mol} / \mathrm{m}^{2} \mathrm{~s}$, at 27 ${ }^{\circ} \mathrm{C}$, at $\mathrm{pH} 7.00$ and air flow rate of $0.50 \mathrm{~L} / \mathrm{min}$.
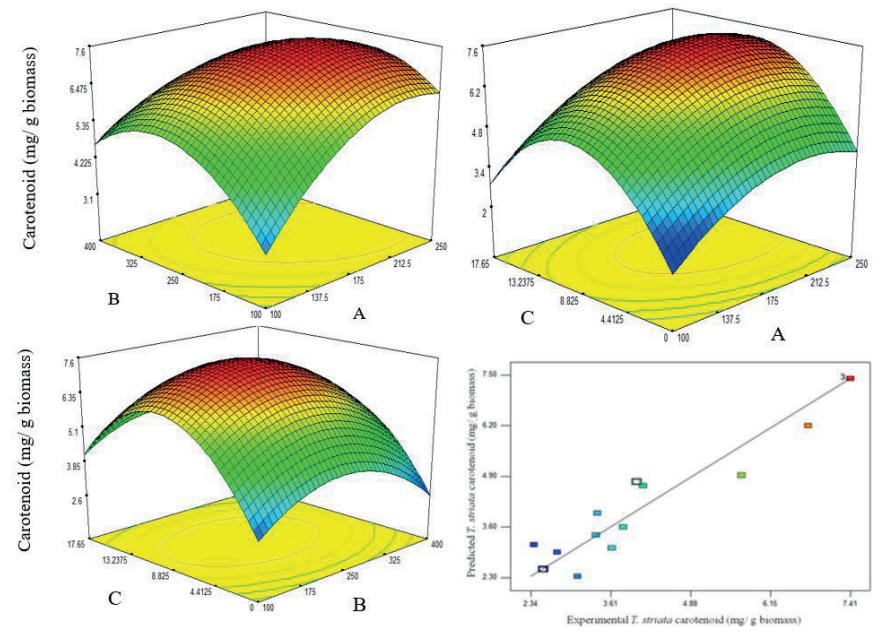

Figure 4. 3D response surface plot of $B B D$ showing the mutual effects of $A$ : Shaking rate (rpm), B: light intensity ( $\mu \mathrm{E} /$ $m^{2} s$ ) and $C$ : nitrogen concentration (mM) on carotenoid concentration of Tetraselmis striata.
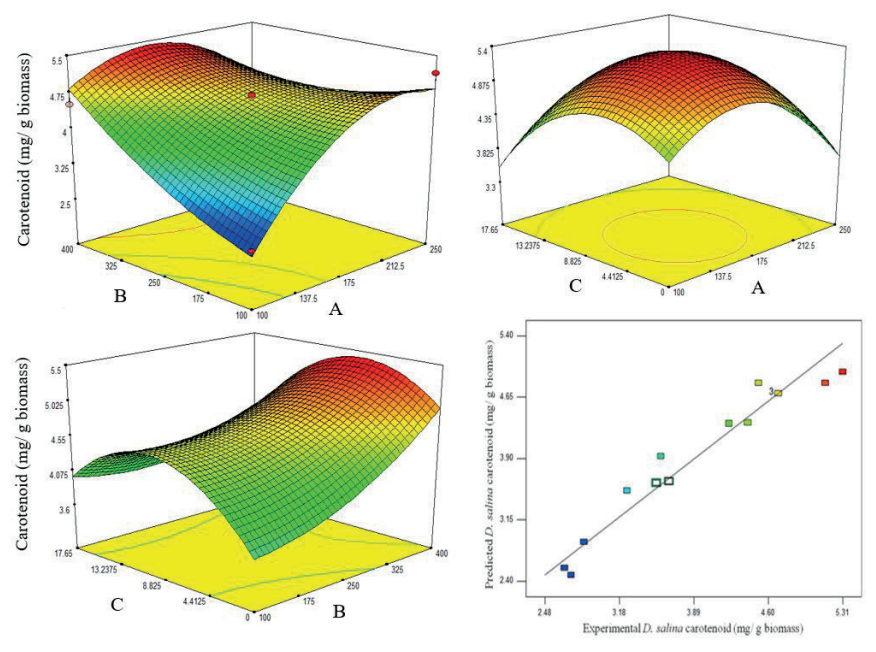

Figure 5. 3D response surface plot of $B B D$ showing the mutual effects of $A$ : Shaking rate (rpm), B: light intensity ( $\mu \mathrm{E} /$ $\mathrm{m}^{2} \mathrm{~s}$ ) and $\mathrm{C}$ : nitrogen concentration $(\mathrm{mM})$ on carotenoid concentration of Dunaliella salina.

Chlorella zofingiensis optimized the Basal medium using a Plackett-Burman design to peruse seven different factors in which glucose, sodium nitrate and magnesium sulfate heptahydrate were identified to maximize both cell growth and astaxanthin production (Chen \&Wang, 2013).

Results of validation studies for experimental and actual data In order to validate findings, microalgae species were grown for 11 days at the values given in table 4 and spectrophotometric carotenoid analyzes were performed. These results ratified the validness of the model, and the trial values are in accord with the predicted values. Carotenoid concentrations increased when the light intensities were raised for C. vulgaris and $D$. salina cultures while maximum carotenoid concentra- 
tion for A. convolutus, T. striata was found under the mild light intensities. This outcome asserts that carotenoids damage is correlate with both the photoprotective role and light-harvesting complexes of carotenoids in the cell compartments, decreasing the singlet oxygen production and scavenging free radicals stimulated by high light and nutrient deficiency (Gonçalves et al. 2019; Faraloni and Torzillo, 2017). Increasing the light intensity resulted in an enhanced ö-carotene productivity in Dunaliella salina (Sun et al. 2018).

\section{Production of microalgae in photobioreactor (PBR)}

At the end of the whole optimization process, the highest amount of microalgae species carotenoid content compared to the total biomass was found in A. convolutus. In view of the results, it was decided to produce a photobioreactor (PBR) using A. convolutus.A Controlled panel photoreceptor was used in Flat-plate PBR for the monitoring production of microalgae (Fig. 6). During the 11 days of production, a pH of 8.36, dissolved oxygen and temperature of $23.04^{\circ} \mathrm{C}$ were set and regulated by the control panel.

After the production in Flat-plate PBR, freeze-dried biomass was found to be $4.55 \mathrm{~g}$ and the total carotenoid was $35.72 \mathrm{mg} / \mathrm{g}$ biomass.

\section{Carotenoid analysis}

Wang et al. (2018) emphasized that the spectrophotometric method used for the content of fucoxanthin in Phaeodactylum tricornutum was easier and faster than high performance liquid chromatography (HPLC). Senge and Senger (1990) reported that neoxanthin, violaxanthin, lutein, $\alpha$-carotene, $\beta$-carotene was detected from Ankistrodesmus braunii. All sets, validation and FlatPlate photobioreactor biomass of $A$. convotulus tested, reported the carotenoid profiles and data in Fig. 7, Table 5. Chlorophyta constitutively includes the carotenoids, such as $\beta$-carotene, violaxanthin, neoxanthin and lutein, besides chlorophyll a and b (Takaichi 2011). Asterarcys quadricellulare PUMCC 5.1.1 produced 47.0, 28.7, 15.5 and $14.0 \mu \mathrm{g} \beta$-carotene, lutein, astaxanthin and canthaxanthin $\mathrm{mg}^{-1}$ dry biomass, respectively (Singh et al., 2019). Lutein is a xanthophylls found in some green microalgae species such as Scenedesmus almeriensis, Muriellopsis sp. and Chlorella zofingiensis (Saha et al., 2020). Violaxanthin, $\beta$-carotene were the major carotenoids identified in the different microalgae strains. Violaxanthin and astaxanthin were presented in all experiments, while $\beta$-carotene was defined in some runs. Astaxanthin, valued as secondary carotenoids under abiotic/biotic stress conditions, was discovered in all of the trial runs in biomass.

Table 4. Results of validation data predicted and experimental carotenoid values.

\begin{tabular}{lccccc}
\hline Microalgae & $\begin{array}{c}\text { Shaking rate } \\
(\mathbf{r p m})\end{array}$ & $\begin{array}{c}\text { Light intensity } \\
\left(\boldsymbol{\mu E} / \mathbf{m}^{2} \mathbf{s}\right)\end{array}$ & $\begin{array}{c}\text { Nitrogen } \\
\text { concentration }(\mathbf{m M})\end{array}$ & $\begin{array}{c}\text { Predicted carotenoid } \\
\text { values (mg/g biomass) }\end{array}$ & $\begin{array}{c}\text { Experimental } \\
\text { carotenoid values } \\
\text { (mg/g biomass) }\end{array}$ \\
\hline C. vulgaris & 100 & 400 & 10.85 & 23.15 & 23.78 \\
A. convolutus & 250 & 200.94 & 11.06 & 21.67 & 24.13 \\
T. striata & 220.17 & 212.78 & 9.15 & 7.51 & 8.59 \\
D. salina & 179.18 & 390.17 & 8.84 & 5.32 & 5.51 \\
\hline
\end{tabular}

Table 5. The results of carotenoid composition obtained by HPLC-DAD analysis*.

\begin{tabular}{lccccc}
\hline & $\begin{array}{c}\text { Violaxanthin } \\
(\mathbf{m g} / \mathbf{g})\end{array}$ & $\begin{array}{c}\text { Astaxanthin } \\
(\mathbf{m g} / \mathbf{g})\end{array}$ & $\begin{array}{c}\text { Chlorophyll a } \\
(\mathbf{m g} / \mathbf{g})\end{array}$ & $\begin{array}{c}\text { Chlorophyll b } \\
(\mathbf{m g} / \mathbf{g})\end{array}$ & $\begin{array}{c}\beta \text {-carotene } \\
(\mathbf{m g} / \mathbf{g})\end{array}$ \\
\hline Run 1 & 0.13 & 0.02 & 5.72 & 5.03 & - \\
Run 2 & 0.47 & 0.04 & 17.94 & 15.39 & - \\
Run 3 & 0.10 & 0.01 & 8.21 & 7.47 & - \\
Run 4 & 0.23 & 0.02 & 1.70 & 2.70 & - \\
Run 5 & 0.18 & 0.09 & 0.52 & 0.80 & - \\
Run 6 & 0.08 & 0.04 & 19.66 & 13.90 & - \\
Run 7 & 0.04 & 0.01 & 3.53 & 3.31 & - \\
Run 8 & 0.29 & 0.05 & 16.72 & 18.16 & - \\
Run 9 & 0.13 & 0.02 & 6.96 & 7.27 & - \\
Run 10 & 0.30 & 0.03 & 9.28 & 9.20 & - \\
Run 11 & 0.13 & 0.02 & 5.72 & 5.03 & 0.41 \\
Run 12 & 0.13 & 0.02 & 5.72 & 5.03 & 0.75 \\
Run 13 & 0.09 & 0.05 & 0.21 & 7.43 & 0.36 \\
Run 14 & 0.05 & 0.03 & 0.39 & 11.50 & - \\
Run 15 & 0.21 & 0.02 & 0.28 & 6.31 & - \\
Validation & 0.21 & 0.03 & 8.22 & 8.62 & \\
Flat- plate photobioreactor & 0.84 & 0.10 & 34.75 & 17.03 & \\
\hline *Results are the data procured from single sample (n=1). & & & & \\
\end{tabular}




\section{CONCLUSION}

In conclusion, growing the green microalgae for the carotenoid production under different light intensity, mixing rate and nitrogen concentration were screened by a Box-Behnken design using spectrophotometric method of total carotenoid. The design emergent in this study through RSM was sufficient for all the essential values it utilized in the optimization. This paper ensures an elaborative study that used both statistical and mathematical methods to detect the optimum levels and interactions among the aforesaid factors in carotenoids production from C. vulgaris, A. convotulus, D. salina, T. striata. The article stated that carotenoid production by microalgae may be increased by optimized culture conditions. Ankistrodesmus convotulus, which cultivated the optimized conditions in $6 \mathrm{~L}$ flat-plate photobioreactor, was given the highest carotenoid concentration. The carotenoid profile was detected by high-performance liquid chromatography (HPLC) with a diode-array detector (DAD) because of separating and identifying photosynthetic pigments.

Microalgal carotenoid production has recently gained much more research interest due to the possibility of commercial applications especially in food, pharmaceutical, and cosmetic industries. Several research groups have recorded their studies on microalgal carotenoid production. On the other hand, to our knowledge, this is the first report showing the study of comprehensive optimization of culture conditions for total carotenoid in local microalgal strains isolated from Turkish fresh and marine water using Response Surface Methodology. There are still challenges related to the microalgal cultivations and extractions of microalgal carotenoids. For the production of high quality microalgal carotenoids, further studies should focus on the cost-effective microalgal carotenoid processes.

\section{Ethics committee approval: None.}

Conflict of interest: The authors declare that they have no conflict of interest.

Financial disclosure: This article was a part of the master thesis with financial support from both the Scientific and Technological Research Council of Turkey-TUBITAK (116Y023) and Ege University Scientific Research Projects-EGE BAP (17BIL008).

Acknowledgements: The authors would like to thank Assistant Professor Tuğba Keskin Gündoğdu for her help with the statistical software.

Availability of data: This paper contains all data analyzed during the study.

Authors' Contributions: Neslihan Sener: Conceptualization; Data curation; Formal analysis; Funding acquisition; Investigation; Software; Validation. Zeliha Demirel: Methodology; Project administration; Resources; Visualization; Writing - review \& editing. Esra Imamoglu: Conceptualization; Data curation; Roles/ Writing - original draft; Writing - review \& editing. Meltem Conk Dalay: Conceptualization; Data curation; Supervision.

\section{REFERENCES}

Ambati, R. R., Gogisetty, D., Aswathanarayana, R. G., Ravi, S., Bikkina, P. N., Bo, L., \& Yuepeng, S. (2019). Industrial potential of carotenoid pigments from microalgae: Current trends and future prospects. Critical reviews in food science and nutrition, 59(12), 1880-1902. [CrossRef]

Bajwa, K., Bishnoi, N. R., Kirrolia, A., Gupta, S., \& Selvan, S. T. (2019). Response surface methodology as a statistical tool for optimization of physio-biochemical cellular components of microalgae Chlorella pyrenoidosa for biodiesel production. Applied Water Science, 9(5), 128. [CrossRef]

Cezare-Gomes, E. A., del Carmen Mejia-da-Silva, L., Pérez-Mora, L. S., Matsudo, M. C., Ferreira-Camargo, L. S., Singh, A. K., \& de Carvalho, J. C. M. (2019). Potential of Microalgae Carotenoids for Industrial Application. Applied biochemistry and biotechnology, 188(3), 602634. [CrossRef]

Chen, T., \& Wang, Y. (2013). Optimized astaxanthin production in Chlorella zofingiensis under dark condition by response surface methodology. Food Science and Biotechnology, 22(5), 1-8. [CrossRef]

Coêlho, D. D. F., Tundisi, L. L., Cerqueira, K. S., Rodrigues, J. R. D. S., Mazzola, P. G., Tambourgi, E. B., \& Souza, R. R. D. (2019). Microalgae: Cultivation Aspects and Bioactive Compounds. Brazilian Archives of Biology and Technology, 62. [CrossRef]

Demirel, Z., Imamoglu, E., Deniz, i., \& Dalay, M. C. Optimization of Cryopreservation Process Using Response Surface Methodology for Chlorella saccharophila and Chlorella zofingiensis. Celal Bayar Üniversitesi Fen Bilimleri Dergisi, 14(4), 405-412. [CrossRef]

Demirel, Z., Yilmaz, F. F., Ozdemir, G., \& Dalay, M. C. (2018). Influence of Media and Temperature on the Growth and the Biological Activities of Desmodesmus protuberans (FE Fritsch \& MF Rich) E. Hegewald. Turkish Journal of Fisheries and Aquatic Sciences, 18(10), 1195-1203. [CrossRef]

Di Lena, G., Casini, I., Lucarini, M., \& Lombardi-Boccia, G. (2019). Carotenoid profiling of five microalgae species from large-scale production. Food research international, 120, 810-818. [CrossRef]

Erdoğan, A., Çağır, A., Dalay, M. C., \& Eroğlu, A. E. (2015). Composition of carotenoids in Scenedesmus protuberans: Application of chromatographic and spectroscopic methods. Food analytical methods, 8(8), 1970-1978. [CrossRef]

Faraloni, C., \& Torzillo, G. (2017). Synthesis of antioxidant carotenoids in microalgae in response to physiological stress. Carotenoids. IntechOpen, 143-157. [CrossRef]

Gonçalves, C. F., Menegol, T., \& Rech, R. (2019). Biochemical composition of green microalgae Pseudoneochloris marina grown under different temperature and light conditions. Biocatalysis and agricultural biotechnology, 18, 101032. [CrossRef]

Keskin Gündoğdu, T., Deniz, I., Çalışkan, G., Şahin, E. S., \& Azbar, N. (2016). Experimental design methods for bioengineering applications. Critical reviews in biotechnology, 36(2), 368-388. [CrossRef]

Novoveská, L., Ross, M. E., Stanley, M. S., Pradelles, R., Wasiolek, V., \& Sassi, J. F. (2019). Microalgal carotenoids: A review of production, current markets, regulations, and future direction. Marine drugs, 17(11), 640. [CrossRef]

Saha, S. K., Ermis, H., \& Murray, P. (2020). Marine microalgae for potential lutein production. Applied Sciences, 10(18), 6457. [CrossRef]

Senge, M., \& Senger, H. (1990). Response of the photosynthetic apparatus during adaptation of Chlorella and Ankistrodesmus to irradiance changes. Journal of plant physiology, 136(6), 675-679. [CrossRef]

Singh, D. P., Khattar, J. S., Rajput, A., Chaudhary, R., \& Singh, R. (2019). High production of carotenoids by the green microalga Asterarcys quadricellulare PUMCC 5.1. 1 under optimized culture conditions. PloS one, 14(9), e0221930. [CrossRef] 
Sun, X. M., Ren, L. J., Zhao, Q. Y., Ji, X. J., \& Huang, H. (2018). Microalgae for the production of lipid and carotenoids: a review with focus on stress regulation and adaptation. Biotechnology for biofuels, 11(1), 272. [CrossRef]

Senaras, A. E. (2019). Parameter optimization using the surface response technique in automated guided vehicles. In Sustainable Engineering Products and Manufacturing Technologies (pp. 187-197). Academic Press. [CrossRef]

Şahin, S., Nasir, N. T. B. M., Erken, I.., Çakmak, Z. E., \& Çakmak, T. (2019). Antioxidant composite films with chitosan and carotenoid extract from Chlorella vulgaris: optimization of ultrasonic-assisted extraction of carotenoids and surface characterization of chitosan films. Materials Research Express, 6(9), 095404. [CrossRef]
Takaichi, S. (2011). Carotenoids in algae: distributions, biosyntheses and functions. Marine drugs, 9(6), 1101-1118. [CrossRef]

Wang, L. J., Fan, Y., Parsons, R., Hu, G. R., Zhang, P. Y., \& Li, F. L. (2018). A rapid method for the determination of fucoxanthin in diatom. Marine drugs, 16(1), 33. [CrossRef]

Wang, S., Cao, M., Wang, B., Deng, R., Gao, Y., \& Liu, P. (2019). Optimization of growth requirements and scale-up cultivation of freshwater algae Desmodesmus armatus using response surface methodology. Aquaculture Research. [CrossRef]

Wellburn, A. R. (1994). The spectral determination of chlorophylls a and $b$, as well as total carotenoids, using various solvents with spectrophotometers of different resolution. Journal of plant physiology, 144(3), 307-313. [CrossRef] 